\title{
Trends and status in resources security, ecological stability, and sustainable development research: a systematic analysis
}

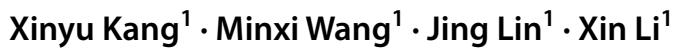 \\ Received: 7 May 2021 / Accepted: 21 February 2022 / Published online: 28 February 2022 \\ (c) The Author(s), under exclusive licence to Springer-Verlag GmbH Germany, part of Springer Nature 2022
}

\begin{abstract}
Resources are essential for human survival and development, and resource security occupies an important position in national security. With the increasing resource shortage problem, ecological stability is facing severe challenges. All countries are actively seeking new sustainable development ways to deal with various issues and shocks caused by the shortage of resources. This study aims to systematically and comprehensively evaluate the knowledge structure, research hotspots, and resource security evolution trends. Based on the number of 6391 articles retrieved from the Web of Science database from 1990 to 2021, this article carried out a visual analysis of global resource security research from the perspectives of scientific output characteristics, keywords, and highly cited literature scientific collaboration networks and hotspot emergence analysis. The research results show that after humans have experienced new public safety incidents, their understanding of resource security and sustainable development has risen to a new height. The number of relevant documents is increasing rapidly. At present, the research on resource security is still dominated by developed countries in Europe and America. This study finds that "food supply chain," "water availability," and "soil resources suitability" are the frontiers and hotspots in the field of resource security. Besides, "biodiversity," "mineral resource security," "medical and health resources" are important topics and directions of current research. This study provides a theoretical basis for scholars to explore the future research direction and practice of resource security, to achieve ecological stability and sustainable development.
\end{abstract}

Keywords Environment $\cdot$ Resource security $\cdot$ Sustainable development $\cdot$ Medical and health resources $\cdot$ Bibliometric analysis · Visualization mapping

\section{Introduction}

Resources are essential for measuring a country's comprehensive strength and the cornerstone of national economic development. With the accelerating process of economic globalization, natural resources are crucial. Various

Responsible Editor: Philippe Garrigues

Minxi Wang

wangminxi@mail.cdut.edu.cn

Xinyu Kang

kangxinyu@stu.cdut.edu.cn

Jing Lin

jeanreen@stu.cdut.edu.cn

Xin Li

lixin2012@cdut.cn

1 College of Management Science, Chengdu University of Technology, Chengdu 610059, China countries have launched fierce competition around the exploration, exploitation, and supply of resources. This indirectly brings a huge challenge to ecological stability. The issue of resource security has become an essential strategic plan for all countries in the world (Peng et al. 2004). Also, the problem of resources security, ecological stability, and sustainable development has become increasingly severe, especially in recent years. The crisis threatening global environmental resilience and human health continues to intensify, such as global temperature rise, sea-level rise, Fukushima earthquake in Japan and the nuclear leakage in 2011, Japanese nuclear wastewater discharge, COVID-19 in 2020, and desertification in Darfur, leading to thoughts and worries about cooperation between countries around the world (Zheng 2017). Resource security and ecological stability are conducive to promoting sustainable urban development and accelerating low-carbon development goals. In this context, global scholars will pay more attention to resource security. To 
deeply understand global resource security research status, it is vital to comprehensively review and summarize the current research achievements in global resource security.

Different scholars have studied the field of resource security. Christina Cook et al. comprehensively reviewed water security from both academic and policy literature, compared the definitions and analyzed methods of water security in different sciences, and put forward the idea of putting good governance first (Cook and Bakker 2012). Ronald Amundson analyzed the difficulties and challenges of policies related to soil resources in the management process (Amundson 2020). Ronald Vargas Rojas studied the relationship between soil health and food security and advocated the establishment of a global soil partnership to achieve world food security (Rojas et al. 2016). Yao Liming explored the relationship between water-energy food and proposed an important method to improve water quality (Yao et al. 2016). This research is of great significance for realizing resource conservation and sustainable development in the future ( $\mathrm{Xu}$ and Yao 2022). Tatiana Ponomarenko (Ponomarenko et al. 2021) and Antoine Beylot (Beylot et al. 2021) conducted in-depth studies on the dilemmas and dissipation of mineral resources. Zeng Xianlai researched the sustainability of critical metals and e-waste management (Zeng et al. 2015; 2018). Also, other scholars have carried out analyses from the aspects of biological resources diversity (Fløjgaard et al. 2020), medical and health resources (Takura et al. 2021), sustainable circulation of water resources (Xiang et al. 2021; Shen et al. 2014; Sutapa et al. 2021), and mineral resource safety (Baninla et al. 2019; Shao 2019; Zhang et al. 2021). Based on the research of scholars, this paper systematically sorts out the research in the field of resource security and provides suggestions for policy.

In recent years, the number of relevant literature on resource security research is increasing, covering a wide range of topics involving multiple disciplinary fields. This brings certain drawbacks to the exploration of emerging research fields, research hotspots, and research frontiers of global resource security. The advent of big data has brought great value to all fields of current society (Wang and $\mathrm{Lu}$ 2020). Data mining, data analysis, and graphics processing technology are widely used in the research of various industries. The combination of computer technology and traditional mathematical statistics makes the visualization analysis of scientometrics possible. Scientometrics can intuitively reflect all the information in the research field through knowledge graphs to explore the research hotspots and future trends in specific fields. It is widely used in medical (Wang et al. 2019), intelligent manufacturing (Asemi and Ko 2020), business economics (Castillo-Vergara et al. 2018), artificial intelligence (Darko et al. 2020; Mustak et al. 2021), and other fields.
In this paper, we will use scientometric research methods from a new research perspective to comprehensively and systematically review relevant research in the field of global resource security and use Rostcm 6 published by Wuhan University and CiteSpace to conduct text mining, cluster analysis, co-citation analysis, network analysis, and emergent analysis to answer the following questions: (1) Which countries or regions, research institutions, and scholars have made outstanding contributions to the development of global resource security research? (2) What are the development trends, research frontiers, and future trends in the field of resource security? (3) Which journals have a significant influence in the field of resource security research? (4) What changes have scholars' attention to resource security research? (5) What areas do international cooperation in resource security involve?

\section{Materials and methods}

\section{Data sources}

At present, the databases commonly used by international experts and scholars include PubMed, Web of Science, Scopus, and Google Scholar (Liao 2009). Each of these databases has its unique advantages and disadvantages. The best results can be obtained when using the PubMed database for keyword retrieval. It is mainly based on biomedical electronic research but lacks data from other fields (Falagas et al. 2008). Scopus database covers a wider range of journals. It can better provide keyword search and citation research. However, the Web of Science database is limited to recent publications (published after 1995) (Falagas et al. 2008; Anker et al. 2019; Chertow et al. 2021). As a bibliometric data collection tool, the Google Scholar database has a wide range of research, but the data quality is relatively low, and the repetition rate is high (Bar-Ilan 2010; Harzing 2019). Web of science is a comprehensive database (Orduna-Malea et al. 2019). It provides unified and standardized literature, which can better visualize the collected data. Most scholars prefer the Web of Science database for bibliometric and visual analysis (Chen et al. 2020; Radu et al. 2021).

Based on these reasons and to ensure the reliability of the data, this paper selected the core databases in Web of Science: Sci-Expanded, Ccr-Expanded, SSCI, and Index Chemicus to retrieve relevant literature data. The data collection method and scientometric analysis structure adopted are shown in Fig. 1. The determined search formula is $\mathrm{TS}=$ (global resource security) $\mathrm{OR}$ $\mathrm{TS}=($ global resource safety) $\mathrm{OR} \mathrm{TS}=$ (zero risk of global resources) OR TS $=$ (International resource security) OR $\mathrm{TS}=($ International resource safety $)$ OR TS $=$ (zero risk of international resources) AND PY $=(1990-2021)$. 


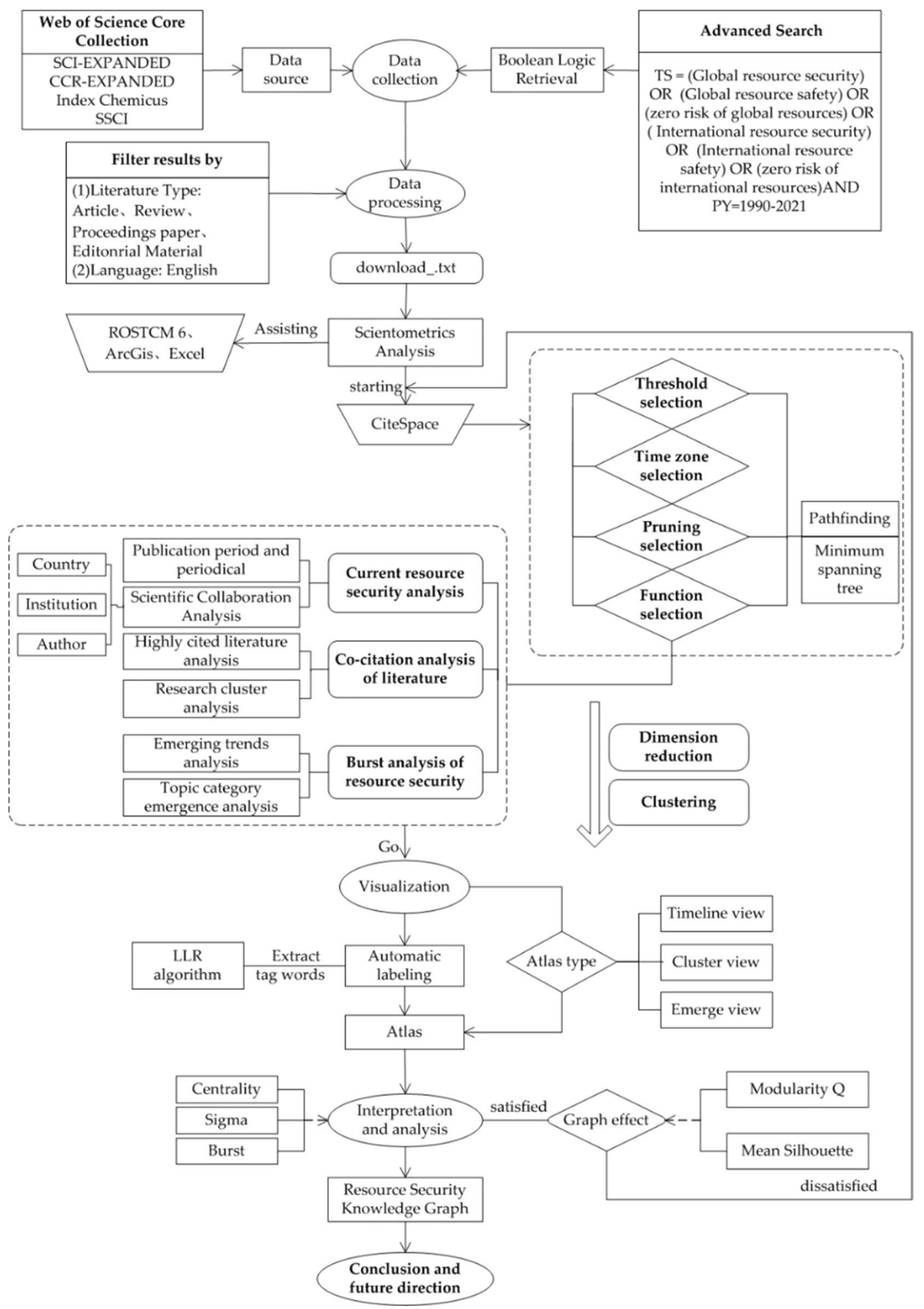

Fig. 1 The research framework of resource safety

TS = "Topic" is the expression used in Web of Science for advanced retrieval and then manually remove literature not related to this research topic. The literature analyzed in this paper does not include "gray literature" such as reports because such literature does not have the standard format for CiteSpace analysis. They will not have an excessive impact on the results of the visualization analysis (Hou et al. 2018). 


\section{Research methods and tools}

Bibliometrics is a statistical method to quantitatively analyze scientific literature by applying the relevant theories of mathematics and statistics. By collecting and comparing papers from different sources in a specific research field, this paper summarizes the number of publications, research hotspots, and research methods to analyze the current research status and trends. Scientific knowledge mapping (mapping knowledge domains) is a kind of image that takes the knowledge domain as the research object. It shows the relationship between the development process and the structure of scientific knowledge. Also, it can help researchers analyze, judge, and predict the development dynamics and disciplinary frontier trends of certain subject areas (Chen 2006; Guo et al. 2015; Chen et al. 2015).

Among the numerous bibliometrics and knowledge mapping tools, CiteSpace developed by Professor Chen Chaomei from Drexel University in the USA is highly favored and recognized by researchers (Chen et al. 2014). This software is an information visualization software developed based on Java language (Liao 2009), which can present knowledge structure, distribution, and law through visualization. It is also commonly used to draw scientific knowledge maps to explore research hotspots, research frontiers, and research trends (Hou et al. 2018), specifically national cooperative research, institutional cooperative research, and author cooperative research. In this paper, we use CiteSpace 5.5 R2 as a metrological tool to visually analyze the knowledge structure, law in the field of global resource security, and conduct a co-citation analysis of relevant literature to explore knowledge clustering and distribution. At the same time, it carries out a detailed analysis of the cited literature to clarify the research hotspots and frontiers at this stage. Finally, based on the results of quantitative analysis, it constructs the knowledge map of global resource security research.

\section{Results}

\section{Analysis of publication types and periodicals}

The number of scientific achievements can reflect the degree of scholars' attention to a certain field. This paper retrieved 6391 literature data about global resource security, including 4973 articles, 1036 reviews, 255 proceedings papers, and 127 Editorial materials. The paper used the data analysis software ROSTCM 6 and the Excel tool to carry out statistics and draw the histogram, as shown in Fig. 2. From the time dimension distribution of literature publication quantity, the number of articles on resource security has increased exponentially, from 8 in 1995 to 978 in 2020; from another perspective, resource security-related research is receiving increasing attention from society and scholars from all walks of life. Besides, the growth rate of the literature can be roughly divided into three stages: the first stage is from 1995 to 2003; the number of literature grew slowly, and researchers started to explore the field of resource security; the second stage is from 2004 to 2008; the number of literature reached a rapid growth. After the SARS epidemic in 2003, the concept of human development changed, and people began to realize the importance of "total global work." By sharing and managing global resources and strengthening cooperation, we can ensure orderly and sustainable human civilization (Guo 2004). This may be one of the reasons for the vital turning point of the number of papers in 2003 . The third stage is from 2009 to 2021, the number of articles reached a boom period. The financial crisis has brought
Fig. 2 The number of publications in the global resource safety area from 1995 to 2021

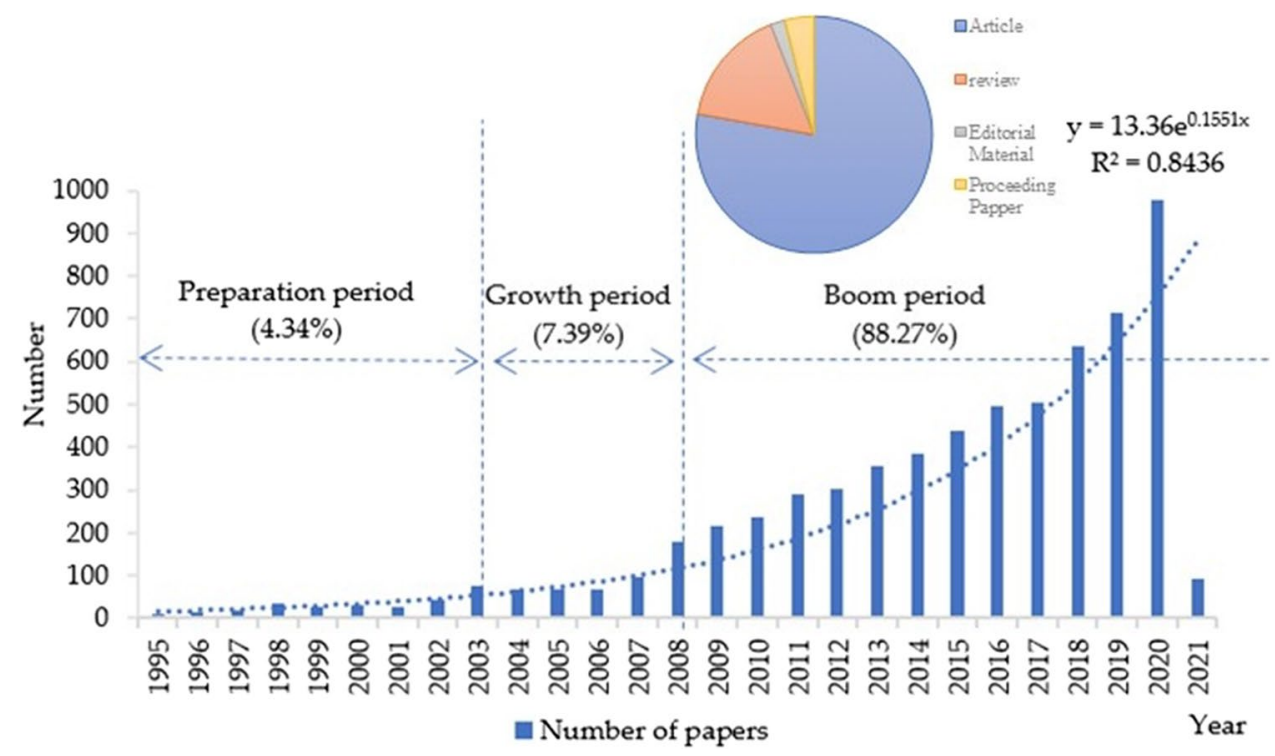


severe challenges to the resource security of all countries, which are gradually realizing that bundled economy will bring greater development conflicts. So far, more and more scholars are devoted to the research of resource security.

From the distribution of journals, we can see that more than 100 journals publish papers related to resource security. In this paper, the top 10 source journals of resource security are selected (as shown in Table 1). It can be seen that "Sustainability" has the largest number of papers published, while the Journal of Cleaner Production and Science of the Total Environment have relatively high impact factors in the top 10 journals, with impact factors of 7.246 and 6.551. The subject categories are "Green \& Sustainable Science \& Technology" and "Environmental Sciences \& Ecology." The discipline of these journals involves multiple disciplines such as Sustainable Science, Ecology Sciences, Environmental Sciences, and Atmospheric Sciences. This shows that the research in the field of resource security is interdisciplinary.

\section{Analysis of scientific cooperation networks}

\section{Analysis of author cooperation}

Scientific cooperation refers to exploring the relationship between different countries, institutions, or authors of the same article. Authors with a large number of literary publications and citations indicate that they have continuous academic commitment and influence in the field of resource security ( $\mathrm{He}$ 2020). The authors' statistical analysis from two aspects can get the core research author in this field more comprehensively and accurately. In bibliometrics, the American scientist Price proposed the famous Lipes law in studying the relationship between the number of scientists and the number of scientists' literature (Ding 1993). According to this law, the authentication formula of the core author is in Formula (1):

$M \approx 0.749 * \sqrt{\text { Nmax }}$ where Nmax represents the researcher with the most published papers and $M$ is the minimum number of published papers. In terms of the number of papers issued, the maximum number of papers published by the authors from 1990 to 2021 was 21 , that is, $\operatorname{Nmax}=21, M \approx 3.432$. Therefore, the number of single authors published in more than four articles was selected as the core authors in this field. According to the statistics, 57 authors have published more than four papers, and these authors have published 312 papers in total. In terms of the number of citations, the author had the highest citation times of 243 times from 1990 to 2021, that is, Nmax $=243, M \approx 11.676$. It indicates that the authors are identified as core authors only when the citation times of their articles are 12 or more. One hundred five authors meet the requirements.

Based on the above two evaluation indexes of core authors, ten authors are meeting both evaluation indexes, the total number of publications is 73 , and the number of cited authors is 818 , accounting for $13.3 \%$ of the total number of cited authors. There is a certain gap between these two data and the 50\% core authors identified in Lipes law. According to CiteSpace analysis, there is a large gap in the cooperation between authors in the field of resource security, some of which are small-scale cooperation between two people and some of which are collective research between most authors. As the core of the collaboration group, Paolo D'odorico, Edward H Allison, and Maria Cristina Rulli are the most significant and most closely connected. The above results indicate that although there are many small-scale exchanges among scholars in this field, on the whole, the sense of cooperation and academic exchanges among scholars need to be strengthened (Fig. 3).

\section{Analysis of collaborating institutions}

According to the statistical results, there are 357 institutions worldwide researching resource security. This paper selects

Table 1 The top 10 journals in terms of publications

\begin{tabular}{llll}
\hline Source publication & Number & Impact factor & Categories \\
\hline Sustainability & 116 & 2.56 & Environmental Sciences \\
Journal of Cleaner Production & 74 & 7.246 & Green \& Sustainable Science \& Technology \\
Renewable Sustainable Energy Reviews & 64 & 5.042 & Environmental Sciences \& Ecology \\
Energy Policy & 58 & 6.096 & Meteorology \& Atmospheric Sciences \\
Plos One & 56 & 3.227 & Science \& Technology-Other Topics \\
Environmental Research Letters & 51 & 6.096 & Meteorology \& Atmospheric Sciences \\
Science of the Total Environment & 51 & 6.551 & Environmental Sciences \& Ecology \\
Food Security & 45 & 3.285 & Food Science \& Technology \\
Marine Policy & 43 & 3.342 & Environmental Sciences \& Ecology/International Relations \\
Water & 41 & 2.544 & Environmental Sciences \& Ecology/Water Resources \\
\hline
\end{tabular}




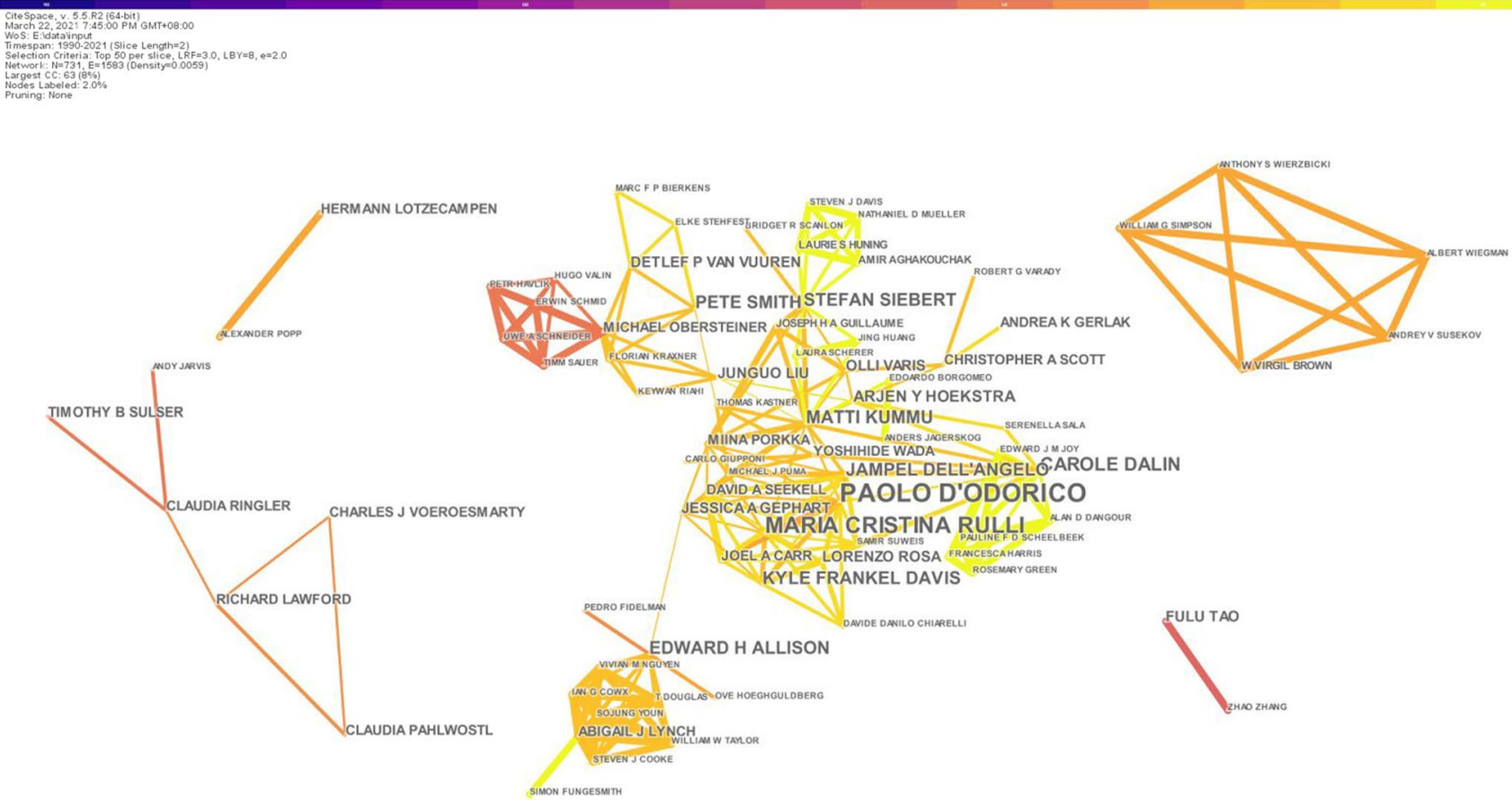

Fig. 3 Knowledge graph of author cooperation

the top ten institutions for statistics (according to the number of documents) and draws Table 2.

As can be seen from the table, the Chinese Academy of Sciences published the most significant number of articles in resource security, followed by the University of British Columbia and the University of Oxford (England). Overall, three of the top 10 institutions (in order of publication volume) are from the USA, and two are from Australia. China, Canada, England, and the Netherlands have one institution in the top ten. The analysis shows that the prominent institutions in resource security research are still developed countries at this stage. Developing countries account for a relatively small proportion in comparison. Figure 4 shows the cooperation graph among institutions. Most of the color lines are purplered, and purple outer circles appear in institutions such as the University of Washington, University of Melbourne, and Sheffield. It indicates that these institutions have high intermediate centrality. These institutions play an essential role in cooperation in resource security.

\section{Analysis of collaborating countries}

Different countries pay different research and attention to the field of resource security. According to the number of published papers, this paper selects the top 10 countries.
Table 2 The top 10 institutions in terms of publications

\begin{tabular}{llll}
\hline Cooperative organization & Freq & $\begin{array}{l}\text { Percentage of total } \\
\text { publications (\%) }\end{array}$ & Centrality \\
\hline Chinese Academy of Science (China) & 147 & 2.30 & 0.06 \\
University of British Columbia (Canada) & 82 & 1.28 & 0.06 \\
University of Oxford (England) & 71 & 1.11 & 0.17 \\
Wageningen University \& Research (Netherlands) & 69 & 1.08 & 0.08 \\
University of Washington (America) & 64 & 1.00 & 0.15 \\
World Health Organization (United Nations) & 64 & 1.00 & 0.12 \\
University of Sydney (Australia) & 62 & 0.97 & 0.07 \\
University of Queensland (Australia) & 55 & 0.86 & 0.05 \\
Harvard University (America) & 53 & 0.83 & 0.03 \\
Columbia University (America) & 51 & 0.80 & 0.04 \\
\hline
\end{tabular}




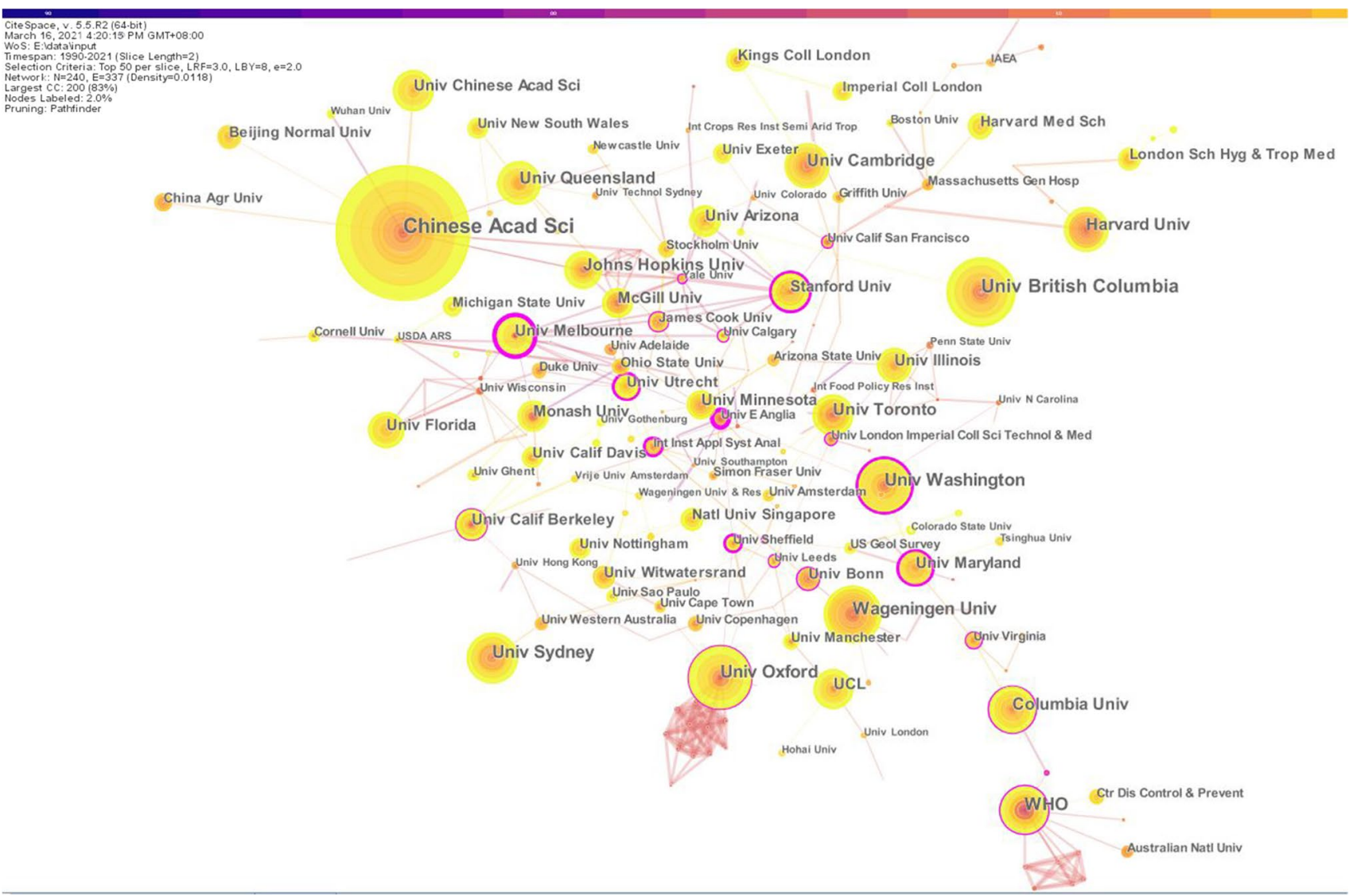

Fig. 4 Knowledge graph of institution cooperation

The sigma value is calculated by centrality and saliency. Generally, the node with higher centrality and emergent will have a higher sigma value. It means that the structure and citation changes are significant (Chen 2011). "Peoples $R$ China" is the abbreviation of "China" in the Web of Science database. This paper uses "China" to express. As shown in Fig. 5, the USA is the country with the largest number of published papers in the field of resource security in the world, with a total of 2145 papers, accounting for $33.6 \%$ of the total number of papers, followed by England (14.8\%), China (11.0\%), Australia (9.5\%), Germany (7.6\%), Canada (7.6\%), Italy (5.8\%), the Netherlands (5.8\%), India (5.4\%), and France (4.4\%). In the top ten, only Peoples R China and India are the two developing countries located in Southeast Asia, while the rest are developed countries distributed in Europe, Australia, and the USA. This shows that the research on resource security is still mainly in developed countries, and the progress of developing countries is relatively slow.

This article plots the cooperation between countries. More connecting lines between developed countries are in the USA, the UK, and Canada. It indicates that cooperation and exchanges between countries are closer. From the perspective of intermediary centrality, Switzerland has the highest centrality with a centrality value of 0.13 . It can be illustrated by the purple circle around the country map. Mexico ranks second with a centrality value of 0.12 . Therefore, Switzerland, Mexico, and Kenya can significantly influence the research trend in resource security. The different colors in the nodes represent the distance of published literature in the country, and the distance from cold colors to warm colors represents the distance from far to near. The red circle on the node has seen an enormous increase in research in this area over a while. In the figure, the USA has the coldest colors. It indicates that the USA started to study the field of resource security in the early period and has a specific research foundation. China's Taiwan, Uganda, Switzerland, and other regions with high emergence value significantly promote research development in this field. In general, the development of resource security is inseparable from the joint efforts of all countries (Fig. 6).

\section{Literature co-citation analysis}

Cross-referencing between scientific literature can show that the literature is not an isolated individual but an interconnected and ever-extending system. In 1973, American 


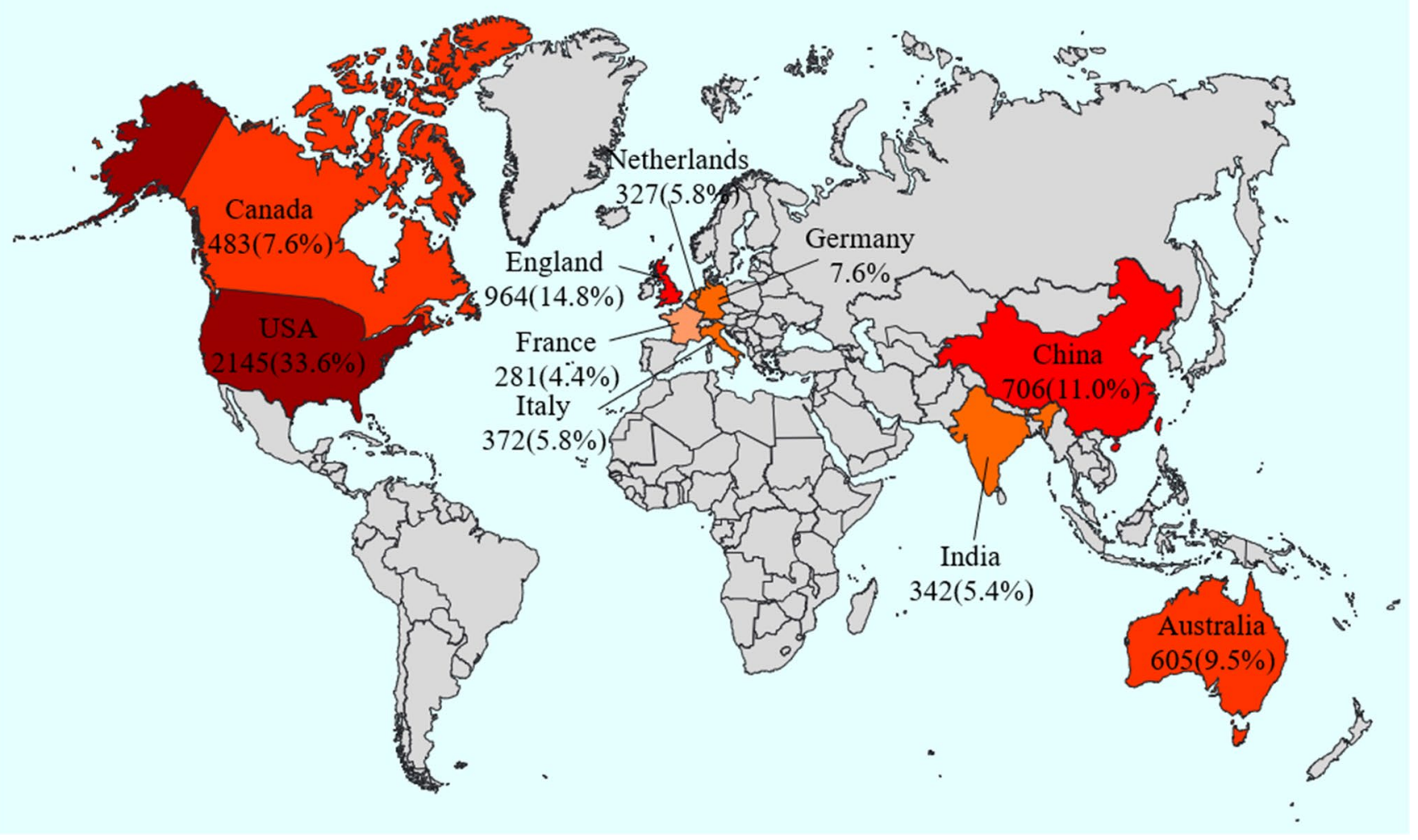

Fig. 5 Top 10 research papers on country distribution maps

Fig. 6 Knowledge graph of country cooperation

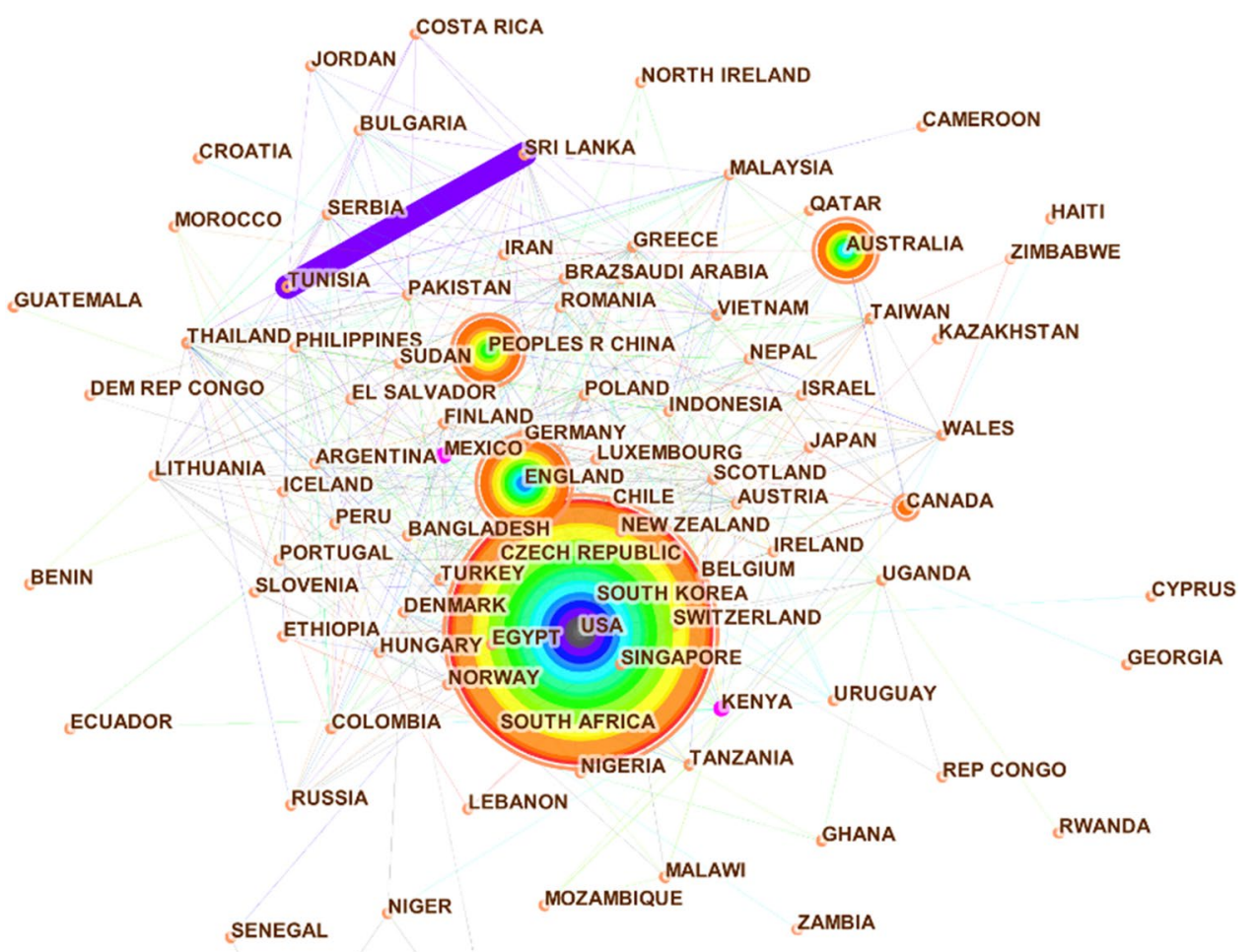

BURKINA FASO 
intelligence scientist Small H first proposed the concept of co-citation as a method to measure the degree of relationship between documents (Small 1973). Co-citation refers to the relationship between two or more papers that are cited by one or more subsequent papers at the same time (Barlow et al. 2017). Therefore, the relationship between these two papers is called co-citation. Generally, highly cited literature shows the hot research in a field, and highly cited authors are considered to have a higher influence in related research fields. Thus, literature co-citation analysis using CiteSpace can discover the key literature and main research areas of resource security research.

\section{Research cluster analysis}

In the cluster analysis of literature, CiteSpace software obtained a relatively high value of clustering results after several debugs, and its parameters were set as follows: timespan 1990-2021, time slice selected as 3, screening criteria as top 20, and log-likelihood ratio algorithm (LLR) was used to label the clusters. When the value of modularity $\mathrm{Q}$ in the clustering results is $>0.3$ and mean silhouette is $>0.5$, the clustering effect is significant. As shown in Fig. 7, there are 12 major clusters formed in this paper. The colors of different clustering blocks in the figure vary from cold to warm, representing the average clustering time from far to near. The red nodes in the color block represent the literature with emergent characteristics. The red nodes indicate that the clustering topic is the research frontier and hotspot.

To further understand the themes of the clusters, this paper summarizes the detailed information of clustering and makes it into Table 3. Mean (year) in Table 3 represents the average time of publication in the same cluster. It can be used to determine the migration pattern of research in resource security. As shown from Table 3, the Silhouette values of the clusters are all greater than 0.7 . So, it indicates that the clusters have certain reliability. According to Fig. 7 and Table 3, the current collections of "food supply chain," "water availability," "wastewater," and "soil resources suitability" are the frontiers and hotspots of research in the field of resource security. Besides, "sanitation and health resources," "nutrient management," "biodiversity," and "food resources safety" are essential topics and directions of the current global resource security research.

\section{Analysis of highly cited literature}

Usually, scholars quoted the previous research results in their papers and sorted them out as references to measure

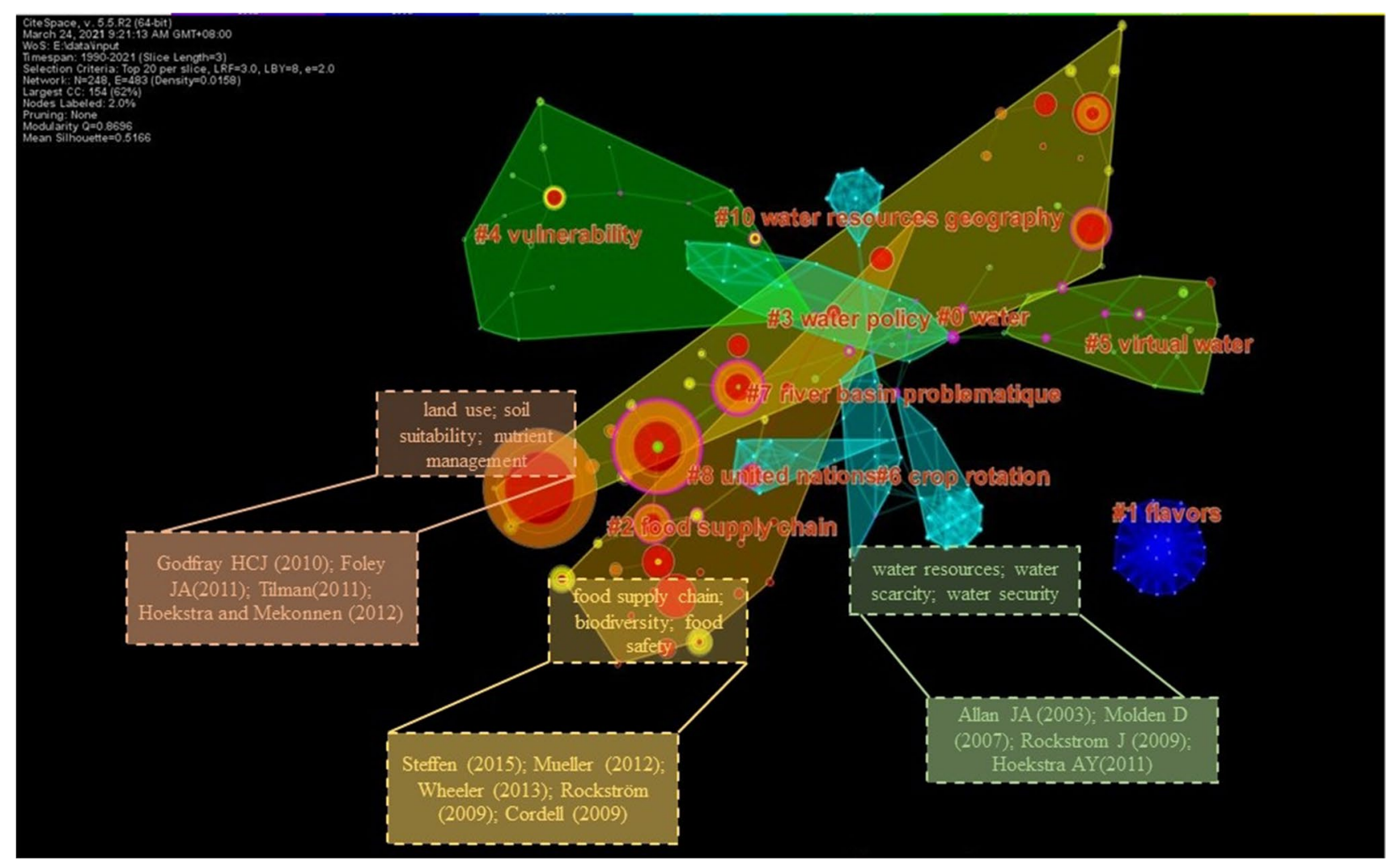

Fig. 7 Cluster network for the resource safety research area 
Table 3 Main clusters in the resource safety research area

\begin{tabular}{lllll}
\hline Cluster ID & Size & Silhouette & Mean (year) & Label (LLR) \\
\hline 0 & 30 & 0.958 & 2011 & Land use; soil suitability; nutrient management \\
2 & 23 & 0.985 & 2014 & Food supply chain; biodiversity; food safety \\
1 & 23 & 1 & 1992 & Urban sustainability; environmental indicator; scarce mineral resources \\
3 & 19 & 0.912 & 2001 & Sustainable development; biofuels; planetary health \\
4 & 17 & 0.958 & 2006 & Fisheries management; soil degradation; pandemic \\
5 & 15 & 0.95 & 2006 & Sanitation and health resources; macronutrients; policy management \\
6 & 14 & 0.863 & 1999 & Soil fertility; food policy; agricultural policy \\
7 & 11 & 0.794 & 1998 & River basin problematic; resources circulation model \\
8 & 9 & 0.898 & 1998 & Water policy; water resources; water scarcity; water security \\
11 & 8 & 0.987 & 1996 & Food waste; food production; mineral fertilization \\
10 & 8 & 0.974 & 1999 & Water availability; wastewater \\
\hline
\end{tabular}

the law of scientific development. This paper compiled the information of the top 10 most cited articles, as shown in Table 4 . The main clusters are in clusters \#0 and \#2. Therefore, we can assume that these two clusters focus on resource security research. The amount of citations in the paper is not the number of sources in WOS but is limited to the cross citations among 6391 articles. The most cited article is "Food security: the challenge of feeding 9 billion people" by Godfray HCJ (Godfray 2010). The growing population and consumption have led to a sharp increase in food demand. The fierce competition in land resources, water resources, and energy resources will affect food production capacity. Therefore, the author explored a multi-level and interconnected global strategy to ensure sustainable and equitable food security. Foley JA deeply analyzes the safety and sustainability of food resources. He put forward recommendations and outlooks from reducing the environmental impact of agriculture, increasing cropping rates, and closing "yield gaps" on underperforming lands (Foley et al. 2011). Besides, Cordell D explored the current and future supply of resources in the context of food resources, suggesting the need to pay attention to issues such as resource shortages (Cordell et al. 2009). The rest of the articles are mainly about food resources, water security, and water flow footprint. Most of these ten highly cited pieces of literature are from "Science" and "Nature" journals.

\section{Emergent analysis in the field of resource security}

\section{Analysis of emerging development trends}

Emergent words tend to judge the evolution and development of a field. They refer to words that frequently appear in a certain period, and the degree of change can reflect the research hotspots in this field (Chen et al. 2012). In the burst test, if there exists a cluster collection containing many articles with emergent words, this cluster collection is an emerging trend. In this paper, after using CiteSpace to analyze the relevant data, we found a lot of literature on emergence. Therefore, the top 10 articles in the emergence ranking are selected here (as shown in Table 5).

Six articles are overlapped among the top 10 highly cited literature and the top 10 highly prominent articles. Most

Table 4 The top 10 cited documents in global resource safety

\begin{tabular}{|c|c|c|c|c|c|c|}
\hline Rank & Author & Freq & Journal & Year & Cluster ID & Literature \\
\hline 1 & Godfray HCJ & 162 & Science & 2010 & 0 & Godfray et al. (2010) \\
\hline 2 & Foley JA & 129 & Nature & 2011 & 0 & Foley et al. (2011) \\
\hline 3 & Tilman D & 77 & Proceedings of the National Academy of Sciences & 2011 & 0 & Tilman et al. (2011) \\
\hline 4 & Steffen W & 67 & Science & 2015 & 2 & Steffen et al. (2015) \\
\hline 5 & Vorosmarty CJ & 65 & Nature & 2010 & 0 & Vörösmarty et al. (2010) \\
\hline 6 & Hoekstra AY & 58 & Proceedings of the National Academy of Sciences & 2012 & 0 & Hoekstra and Mekonnen (2012) \\
\hline 7 & Mueller ND & 56 & Nature & 2012 & 2 & Mueller et al. (2012) \\
\hline 8 & Wheeler T & 51 & Science & 2013 & 2 & Wheeler (2013) \\
\hline 9 & Rockstrom J & 42 & Water Resources Research & 2009 & 2 & Rockström et al. (2009) \\
\hline 10 & Cordell D & 42 & Global Environmental Change & 2009 & 2 & Cordell et al. (2009) \\
\hline
\end{tabular}


papers are published in "Nature," "Science," and "Global Environmental Change." The result shows that the research direction of these scholars is still the research and hotspot in recent years and for a long time in the future. According to the ranking of the burstiness, this study gets the conclusion through further analysis and finds that five of the top 10 highly cited papers belong to cluster \#2. It reflects that "biodiversity," "food resources safety," and "food supply chain" are emerging research trends in the field of resource security. Godfray HCJ in cluster \#0 has the highest emergent ranking, which means that "land resources use," "medical and health resources," "medical and health resources," "food resources supply" are necessary research fields. Resource security affects people's lives and development. What kind of situation the resources will be in in the future and how they will affect people's health are also essential development directions.

Through the analysis of keywords, this paper finds the fast-growing topics in resource security. As shown in Fig. 8, the keywords with a burst ranking of the top 20 are selected and shown in Table 6. As shown in Fig. 8, the keywords with a burst ranking of the top 20 are selected and shown in Table 6. Resource security development can be divided into three stages: the first stage is 1999-2010, the second stage is 2011-2016, and the third stage is 2017-2021. The first phase is the beginning of resource security. The World Conference on Environment and Development in 1992 formally proposed a sustainable development strategy with

Table 5 The top 10 references with the strongest citation bursts

\begin{tabular}{|c|c|c|c|c|c|}
\hline References (DOI) & Cluster\# & Strength & Year & Begin & End \\
\hline Godfray HCJ, 2010, SCIENCE, V327, P812 (Godfray et al. 2010) & 0 & 24.51 & 2010 & 2013 & 2018 \\
\hline Foley JA, 2011, NATURE, V478, P337 (Foley et al. 2011) & 0 & 17.83 & 2011 & 2012 & 2019 \\
\hline Steffen W, 2015, SCIENCE, V347, P0 (Steffen et al. 2015) & 2 & 14.85 & 2015 & 2016 & 2021 \\
\hline Mueller ND, 2012, NATURE, V490, P254 (Mueller et al. 2012) & 2 & 14.18 & 2012 & 2014 & 2018 \\
\hline Rockstrom J, 2009, NATURE, V461, P472 46 (Rockström et al. 2009) & 2 & 13.34 & 2009 & 2011 & 2016 \\
\hline Cordell D, 2009, GLOBAL ENVIRON CHANG, V19, P292 (Cordell et al. 2009) & 2 & 13.34 & 2009 & 2011 & 2016 \\
\hline Mekonnen MM, 2016, SCI ADV, V2, P0 (Mekonnen and Hoekstra 2016) & 0 & 12.27 & 2016 & 2014 & 2016 \\
\hline Tilman D, 2014, NATURE, V515, P518 (Tilman and Clark 2014) & 2 & 11.99 & 2014 & 2017 & 2021 \\
\hline Lobell DB, 2008, SCIENCE, V319, P607 (Lobell et al. 2008) & 4 & 11.05 & 2008 & 2009 & 2014 \\
\hline Schmidhuber J, 2007, P NATL ACAD SCI USA, V104, P19703 (Josef Schmidhuber 2007) & 0 & 10.63 & 2007 & 2011 & 2013 \\
\hline
\end{tabular}

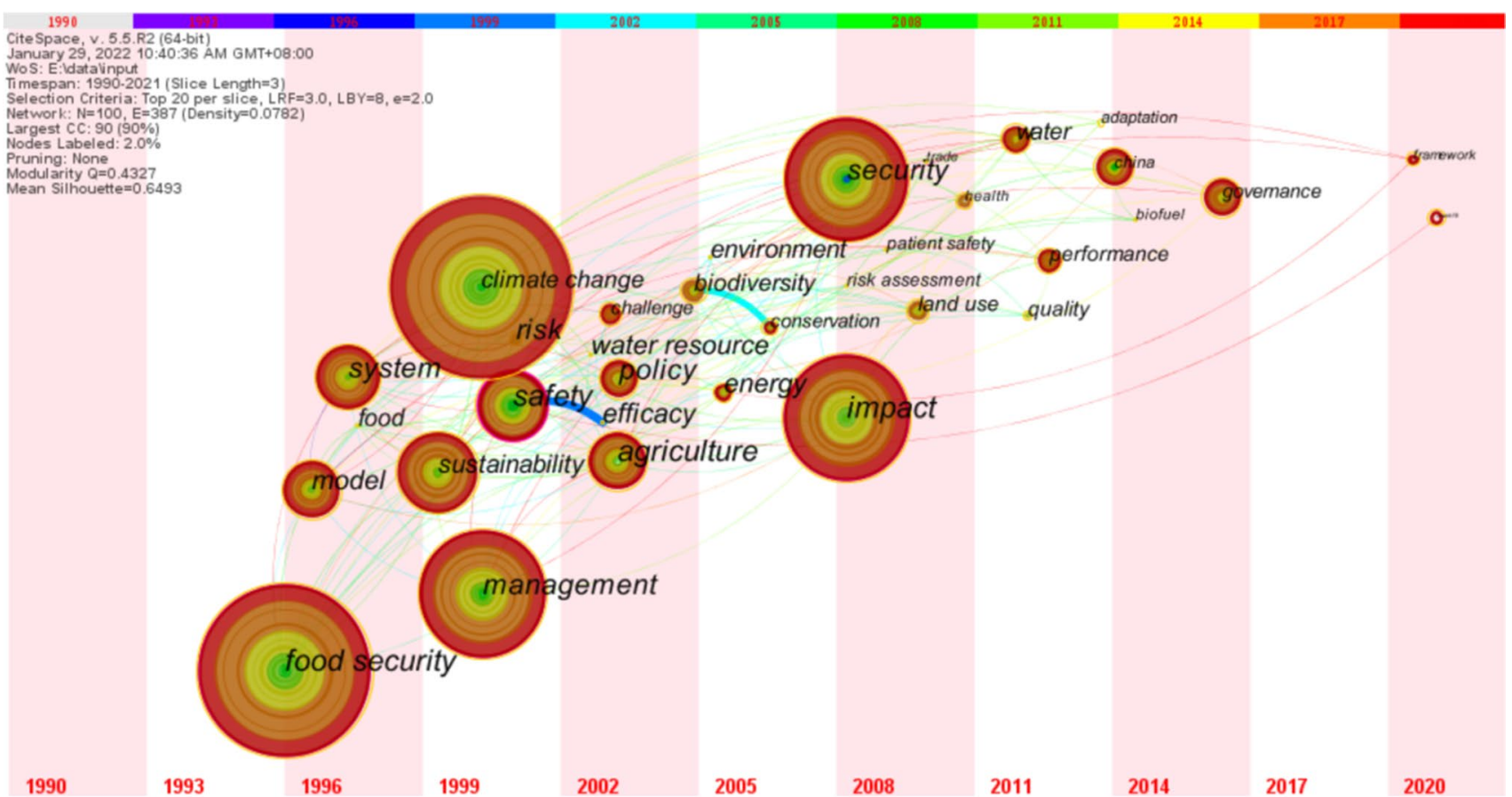

Fig. 8 A time zone view in the global resource security field: 1990-2021 
Table 6 The top 20 keywords analyze with bursts

\begin{tabular}{llrll}
\hline Rank & Keywords & Strength & Begin & End \\
\hline 1 & Developing country & 10.9968 & 1999 & 2010 \\
2 & Risk & 14.6715 & 2000 & 2016 \\
3 & Efficacy & 9.3634 & 2000 & 2010 \\
4 & Water resource & 7.3484 & 2000 & 2010 \\
5 & Food & 11.1845 & 2005 & 2013 \\
6 & Energy & 8.4212 & 2008 & 2015 \\
7 & Trade & 5.487 & 2008 & 2010 \\
8 & Biofuel & 5.487 & 2008 & 2010 \\
9 & Vulnerability & 5.1202 & 2008 & 2010 \\
10 & Quality & 14.0538 & 2011 & 2016 \\
11 & Africa & 9.0116 & 2011 & 2013 \\
12 & Adaptation & 8.4651 & 2011 & 2013 \\
13 & Biodiversity & 11.2069 & 2014 & 2018 \\
14 & Land use & 11.1432 & 2014 & 2019 \\
15 & Conservation & 7.8224 & 2014 & 2016 \\
16 & Challenge & 13.5677 & 2017 & 2021 \\
17 & Health & 12.5821 & 2017 & 2019 \\
18 & Care & 9.7605 & 2017 & 2019 \\
19 & Performance & 4.3545 & 2017 & 2021 \\
20 & China & 6.2607 & 2018 & 2021 \\
\hline
\end{tabular}

"sustainable development" (Weiss 1992). Since then, countries worldwide have begun to pay attention to the importance of strengthening cooperation and "global all-around work." The research purpose of resource security is mainly to analyze the influencing factors of food resources, food resources risks faced by developing countries, pollution prevention and control of water resources, excessive burning of biological fossil fuels, and other issues. So, it can ensure that resources can meet the needs of human future development. In the second stage, with the development of the social economy, people pay more attention to the limitation of resource supply. The ecological and environmental problems caused by excessive exploitation and improper protection of natural resources are becoming increasingly severe. Therefore, this stage mainly focuses on the extensive use of land resources, the security of biological resource diversity, and the restoration of ecosystems. In the third stage, with the deepening of the research, the focus tends to focus on human health. Especially after the outbreak of COVID-19 in 2019, many global social problems and medical resources were directly exposed. At this stage, the research in resource security is more biased toward health care resources, studying the equity and rationality of health care resources and their allocation. The above analysis shows that research in resource security will change over time.

\section{Thematic categories burst analysis in resource security research}

After the above research, we know that the current resource security field involves many fields such as Environmental Sciences, Ecology, Agriculture, Energy \& Fuels, Food Science \& Technology, and Health Policy \& Services. This paper carries out the burst detection of topic categories, analyzes the data through CiteSpace, selects different node categories, sets the time domain, and finally obtains the topic category co-occurrence network of resource security research. Subsequently, we list the top 10 topic categories with high burstiness, as shown in Table 7 . The results show that Green \& Sustainable Science \& Technology and Computer Science are the latest emergent topic categories in resource security.

Table 7 The top 10 subject categories with bursts

\begin{tabular}{|c|c|c|c|c|}
\hline Subject categories & Strength & Begin & End & 1990-2021 \\
\hline $\begin{array}{l}\text { COMPUTER SCIENCE, } \\
\text { INFORMATION SYSTEMS }\end{array}$ & 9.055 & 1996 & 2006 & \\
\hline $\begin{array}{c}\text { PHARMACOLOGY \& } \\
\text { PHARMACY }\end{array}$ & 14.8526 & 2000 & 2010 & \\
\hline POLITICAL SCIENCE & 10.9832 & 2011 & 2012 & \\
\hline INTERNATIONAL RELATIONS & 25.8057 & 2008 & 2013 & \\
\hline GOVERNMENT \& LAW & 25.3142 & 2008 & 2013 & \\
\hline ECONOMICS & 17.1734 & 1998 & 2014 & \\
\hline ENERGY \& FUELS & 9.361 & 2016 & 2018 & \\
\hline $\begin{array}{c}\text { SCIENCE \& TECHNOLOGY - } \\
\text { OTHER TOPICS }\end{array}$ & 13.7001 & 2013 & 2019 & \\
\hline COMPUTER SCIENCE & 14.9074 & 2018 & 2021 & \\
\hline $\begin{array}{l}\text { GREEN \& SUSTAINABLE } \\
\text { SCIENCE \& TECHNOLOGY }\end{array}$ & 10.9656 & 2017 & 2021 & \\
\hline
\end{tabular}




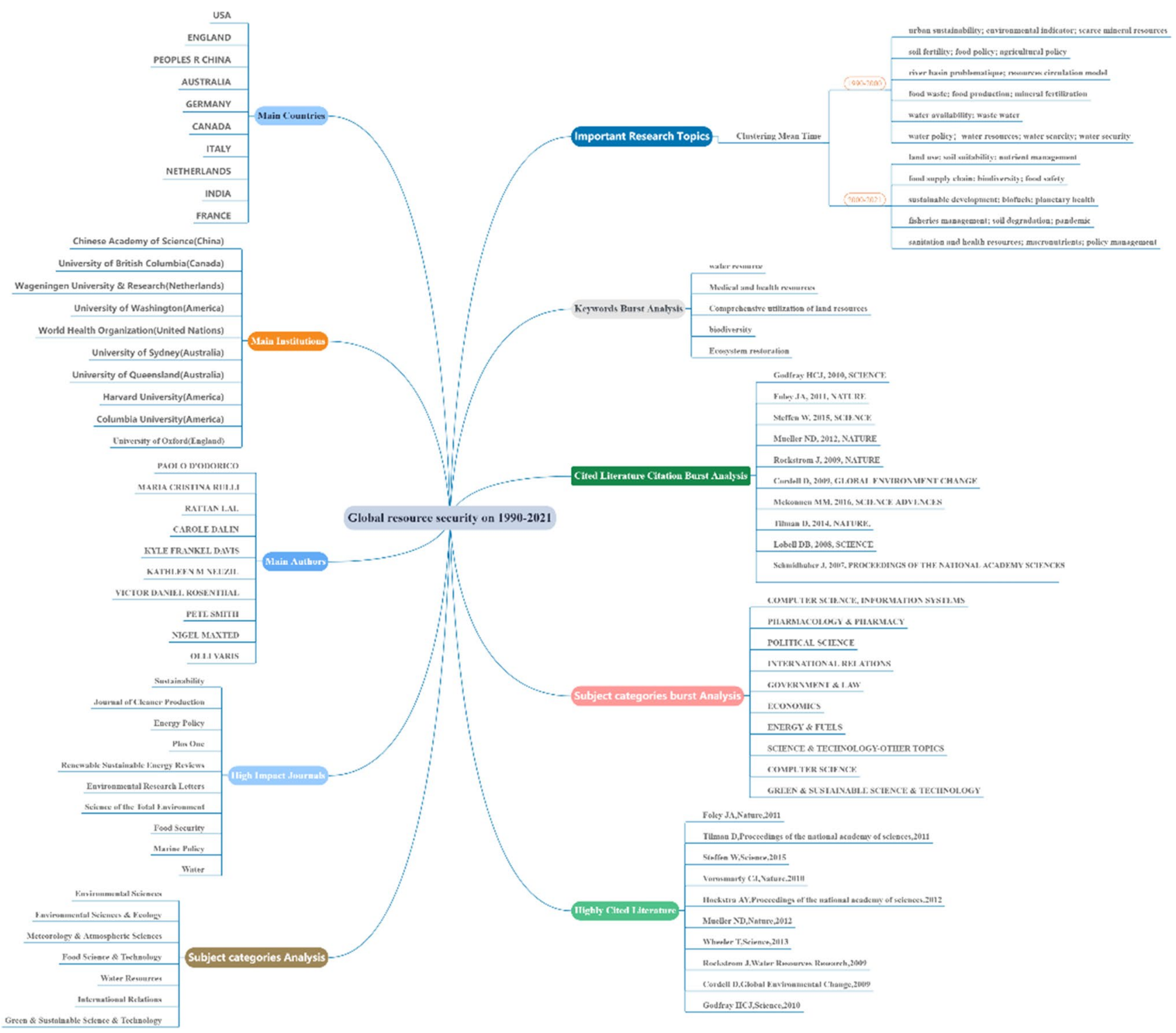

Fig. 9 A comprehensive knowledge map in the global resource security field: 1990-2021

Finally, based on the analysis in the previous sections, this paper draws a comprehensive knowledge map in resource security. It can clarify the cooperative institutions, current research status, and research frontiers in this field in detail, as shown in Fig. 9.

\section{Discussion}

This research finds that the number of articles covering the field of resource security has increased exponentially over the past few decades, from 8 publications in 1995 to 978 publications in 2020. The research areas are broad, covering theories and methods from multiple disciplines. This research indicates that sustainable development research under the combined effect of resource security and ecological stability has attracted scholars' attention. "Sustainability" has the most publications, while "Journal of Cleaner Production" has the highest impact factor in the top ten journals.

Through the research on the number of publications and the number of citations, it is found that the proportion of core authors in the field of resource security does not meet the requirement of Lipes law. Therefore, there are no relatively stable core authors in this field, but a close collaborative group exists. Besides, the Chinese Academy of Science has published the largest number of papers among the research institutions. In recent years, the number of publications in China has been increasing. However, research in resource security is still focused on developed countries (Europe, USA, England, Australia, Germany, Canada), while 
developing countries (China, India) are relatively lacking. The areas of cooperation mainly involve water resources, land resources, and mineral resources. The collaboration between countries, institutions, and researchers should be enhanced. There is an urgent need to promulgate policies to address resource shortages and ecological crises jointly.

This study explores the analysis of literature co-citation. It finds that the article "Food security: the challenge of feeding 9 billion people" by Godfray HCJ is the most cited article among 6391 articles. Sustainable Science \& Technology and Computer Science are the most recent thematic categories in resource security. Most of the highly cited articles are from Science and Nature, and the average research time was in 2010. The safety of food resources is an issue in all countries globally. It is related to the health and happiness of the people and related to the country's public safety. In recent years, there have been many food safety issues globally, such as spoiled beverages, contaminated chocolate, and toxic milk powder, which have brought hidden dangers to people's healthy lives. FAO and World Health Organization pointed out that 420,000 people die from food insecurity every year; at the same time, diseases caused by food insecurity also increase the burden of medical care. Therefore, supply safety, storage safety, and planting safety of food resources will become major issues of long-term concern for scholars, various industries, and even countries in the future.

Besides, research on the integrated use of land resources will be a more active area in the coming decades. From cluster analysis and emergent analysis, we find that "food supply chain," "water availability," "wastewater," and "soil resources suitability" are the frontiers and hotspots of research in the field of resource security. "Sanitation and health resources," "biodiversity," "food resources safety," "land resources use," "medical and health resources," "mineral resource security" are essential topics and directions of current research, especially in the research on medical resources safety and mineral resources safety. After the outbreak of COVID-19 in 2020 , more people began to pay attention to their health and safety. How to coordinate human health development in the allocation of medical resources will focus on the following discussion. The mineral resource industry and supply chain's security have become all countries' attention. Scholars will pay more attention to it in the future.

\section{Conclusion}

Based on the data of 6391 articles on global resource security research retrieved from the Web of Science during 1990-2021, this article carries out a scientometrics analysis of the knowledge structure in this field and draws a comprehensive knowledge map. The research in global resource security is relatively extensive, involving the theories and methods of multiple disciplines. The cooperation among countries in global resource security needs to strengthen. The safe supply of global resources (water, food, medical and health, and mineral resources), prevention mechanisms, policies, and regulations require long-term attention and discussion. People will face more ecological crises and sustainable resource development issues in the future. Therefore, the degree of coupling and coordination among resource security, environmental stability, and sustainable development needs to explore in-depth.

This paper provides a detailed analysis of the scientific output, core authors, critical national institutions, highimpact journals, and citation content in the field of global resource security, thus providing researchers with an overview of the current stage of resource security. Through a more comprehensive and systematic mapping of knowledge in resource security, it is helpful to understand the current knowledge system in global resource security. This research provides valuable guidance for subsequent researchers and related personnel to explore the research direction and practice of resource security, to achieve ecological stability and sustainable development of resources.

Acknowledgements Thanks anonymous peer reviewers for helpful comments on the draft manuscript.

Author contribution Minxi Wang contributed to the conception of the study. Xinyu Kang wrote the original manuscript. Jing Lin performed the data analyses and collection. Xin Li reviewed and revised the manuscript.

Funding This research is funded by the Key Program of Sichuan Mineral Resources Research Center (No. SCKCZY2021-ZD001) and the National Natural Science Foundation of China (71991484 and 71991480).

Data availability We would like to declare that the work described was original research that has not been published previously and is not under consideration for publication elsewhere, in whole or in part.

\section{Declarations}

Ethics approval and consent to participate All the authors listed have approved and participated in the enclosed manuscript.

Consent for publication Publication has been approved by all participants.

Competing interests The authors declare no competing interests.

\section{References}

Amundson R (2020) The policy challenges to managing global soil resources. Geoderma 379:114639

Anker MS, Hadzibegovic S, Lena A, Haverkamp W (2019) The difference in referencing in Web of Science, Scopus, and Google Scholar. ESC Hear Fail 6:1291-1312 
Asemi A, Ko A (2020) The investigation on infoecology in the field of smart manufacturing. Libr Hi Tech

Bar-Ilan J (2010) Citations to the "Introduction to informetrics" indexed by WOS, Scopus and Google Scholar. Scientometrics 82:495-506. https://doi.org/10.1007/s11192-010-0185-9

Baninla Y, Zhang M, Lu Y et al (2019) A transitional perspective of global and regional mineral material flows. Resour Conserv Recycl 140:91-101. https://doi.org/10.1016/j.resconrec.2018. 09.014

Barlow P, McKee M, Basu S, Stuckler D (2017) The health impact of trade and investment agreements: a quantitative systematic review and network co-citation analysis. Global Health 13:1-9

Beylot A, Ardente F, Sala S, Zampori L (2021) Mineral resource dissipation in life cycle inventories. Int J Life Cycle Assess 26:497-510

Castillo-Vergara M, Alvarez-Marin A, Placencio-Hidalgo D (2018) A bibliometric analysis of creativity in the field of business economics. J Bus Res 85:1-9

Chen C (2006) Citespace II: detecting and visualizing emerging trends and transient patterns in scientific literature. J Am Soc Inf Sci Technol 57:359-377

Chen C, Hu Z, Liu S, Tseng H (2012) Emerging trends in regenerative medicine: a scientometric analysis in CiteSpace. Expert Opin Biol Ther 12:593-608

Chen CM (2011) Turning points: the nature of creativity, Beijing and Springer-Verlage Berlin Heidelberg

Chen S, Law R, Xu S, Zhang M (2020) Bibliometric and visualized analysis of mobile technology in tourism. Sustain 12:1-16

Chen Y, Chen CM, Hu ZG (2014) Principles and applications of analyzing a citation space, Science Press

Chen Y, Chen CM, Liu ZY, Hu ZG, Wang XW (2015) The methodology function of CiteSpace mapping knowledge domains. Stud Sci Sci 33:242-253

Chertow MR, Kanaoka KS, Park J (2021) Tracking the diffusion of industrial symbiosis scholarship using bibliometrics: comparing across Web of Science, Scopus, and Google Scholar. J Ind Ecol :1-19

Cook C, Bakker K (2012) Water security: debating an emerging paradigm. Glob Environ Chang 22:94-102

Cordell D, Drangert JO, White S (2009) The story of phosphorus: global food security and food for thought. Glob Environ Chang 19:292-305

Darko A, Chan APC, Adabre MA et al (2020) Artificial intelligence in the AEC industry: scientometric analysis and visualization of research activities. Autom Constr 112:103081

Ding XD (1993) Fundamentals of Bibliometrics. Peking University Press

Falagas ME, Pitsouni EI, Malietzis GA, Pappas G (2008) Comparison of PubMed, Scopus, Web of Science, and Google Scholar: strengths and weaknesses. FASEB J 22:338-342

Fløjgaard C, Valdez JW, Dalby L et al (2020) Dark diversity reveals importance of biotic resources and competition for plant diversity across habitats. Ecol Evol 10:6078-6088

Foley JA, Ramankutty N, Brauman KA et al (2011) Solutions for a cultivated planet. Nature 478:337-342

Guo PY (2004) International cooperation on environmental protection: using SARS as case study. Ecol Econ 8:41-44

Guo Y, Wang XW, He W, Yang MQ (2015) Chinese and international dynamic research into low carbon technology based on bibliometrics and knowledge mapping. Inf Sci 33:139-148

Godfray HCJ, Beddington JR, Crute IR, Haddad L, Lawrence D, Muir JF, Pretty J, Robinson S, Thomas SMCT (2010) Food security: the challenge of the present. Science 327:812-818. https://doi.org/ $10.1126 /$ science. 1185383

Harzing AW (2019) Two new kids on the block: How do crossref and dimensions compare with Google Scholar, Microsoft Academic, Scopus and the Web of Science? Scientometrics 120:341-349
He ZY (2020) Research and evaluation of core authors in the field of studying Miao - territory of Ming and Qing Dynasties in Recent 2 Decades - On the Basis of Price's Law and Comprehensive Index Method. J Panzhihua Univ 37:74-80

Hoekstra AY, Mekonnen MM (2012) The water footprint of humanity. Proc Natl Acad Sci USA 109:3232-3237

Hou J, Yang X, Chen C (2018) Emerging trends and new developments in information science: a document co-citation analysis (2009-2016). Scientometrics 115:869-892

Josef Schmidhuber FNT (2007) Global food security under climate change. Proc Natl Acad Sci 104:19703-19708

Liao YP (2009) Comparative study on PubMed, Web of Science, Scopus and Google Scholar. J Med Informatics 30:18-23

Lobell DB, Burke MB, Tebaldi CMDM, Falcon WPRLN (2008) Prioritizing Climate Change Adaptation Needs for Food Security in 2030. Science 319(80):607-610

Mekonnen MM, Hoekstra AY (2016) Sustainability: four billion people facing severe water scarcity. Sci Adv 2:1-7

Mueller ND, Gerber JS, Johnston M et al (2012) Closing yield gaps through nutrient and water management. Nature 490:254-257

Mustak M, Salminen J, Plé L, Wirtz J (2021) Artificial intelligence in marketing: Topic modeling, scientometric analysis, and research agenda. J Bus Res 124:389-404

Orduna-Malea E, Aytac S, Tran CY (2019) Universities through the eyes of bibliographic databases: a retroactive growth comparison of Google Scholar, Scopus and Web of Science. Scientometrics 121:433-450

Peng SL, Hao YR, Lu HF, Wang BS (2004) The meaning and scales of ecological security. Acta Sci Nat Univ Sunyatseni 43:27-31

Ponomarenko T, Nevskaya M, Jonek-Kowalska I (2021) Mineral resource depletion assessment: alternatives, problems, results. Sustain 13:1-15

Radu V, Radu F, Tabirca AI et al (2021) Bibliometric analysis of fuzzy logic research in international scientific databases. Int J Comput Commun Control 16:1-20

Rockström J, Falkenmark M, Karlberg L et al (2009) Future water availability for global food production: the potential of green water for increasing resilience to global change. Water Resour Res 45:1-16

Rojas RV, Achouri M, Maroulis J, Caon L (2016) Healthy soils: a prerequisite for sustainable food security. Environ Earth Sci 75:1-10

Shao L (2019) Geological disaster prevention and control and resource protection in mineral resource exploitation region. Int $\mathrm{J}$ LowCarbon Technol 14:142-146. https://doi.org/10.1093/ijlct/ctz003

Shen Y, Oki T, Kanae S et al (2014) Projection of future world water resources under SRES scenarios: an integrated assessment. Hydrol Sci J 59:1775-1793. https://doi.org/10.1080/02626667. 2013.862338

Small H (1973) Co-citation in the scientific literature: a new measure of the relationship between two documents. J Am Soc Inf Sci 24:265-269

Steffen W, Richardson K, Rockström J et al (2015) Planetary boundaries: Guiding human development on a changing planet. Science 347:1259855

Sutapa IDA, Apip FM, Yogaswara H (2021) Implementation of ecohydrology to support sustainable water resources management in tropical region, Indonesia. Ecohydrol Hydrobiol 21:501-515. https://doi.org/10.1016/j.ecohyd.2021.08.010

Takura T, Hirano Goto K, Honda A (2021) Development of a predictive model for integrated medical and long-term care resource consumption based on health behaviour: application of healthcare big data of patients with circulatory diseases. BMC Med 19:1-16

Tilman D, Balzer C, Hill J, Befort BL (2011) Global food demand and the sustainable intensification of agriculture. Proc Natl Acad Sci U S A 108:20260-20264

Tilman D, Clark M (2014) Global diets link environmental sustainability and human health. Nature 515:518-522 
Vörösmarty CJ, McIntyre PB, Gessner MO et al (2010) Global threats to human water security and river biodiversity. Nature 467:555-561

Wang W, Lu C (2020) Visualization analysis of big data research based on Citespace. Soft Comput 24:8173-8186

Wang X, Guo J, Gu D et al (2019) Tracking knowledge evolution, hotspots and future directions of emerging technologies in cancers research: a bibliometrics review. J Cancer 10:2643-2653

Weiss EB (1992) United Nations Conference on Environment and Development. Int Leg Mater 31:814-817

von Wheeler TB (2013) Climate change impacts on global food security. Science 341:508-513

Xiang X, Li Q, Khan S, Khalaf OI (2021) Urban water resource management for sustainable environment planning using artificial intelligence techniques. Environ Impact Assess Rev 86:106515

Xu Z, Yao L (2022) Opening the black box of water-energy-food nexus system in China: prospects for sustainable consumption and security. Environ Sci Policy 127:66-76. https://doi.org/10. 1016/j.envsci.2021.10.017

Yao L, Xu J, Zhang M et al (2016) Waste load equilibrium allocation: a soft path for coping with deteriorating water systems.
Environ Sci Pollut Res 23:14968-14988. https://doi.org/10.1007/ s11356-016-6593-5

Zeng X, Li J, Shen B (2015) Novel approach to recover cobalt and lithium from spent lithium-ion battery using oxalic acid. J Hazard Mater 295:112-118. https://doi.org/10.1016/j.jhazmat.2015. 02.064

Zeng X, Mathews JA, Li J (2018) Urban mining of E-waste is becoming more cost-effective than virgin mining. Environ Sci Technol 52:4835-4841. https://doi.org/10.1021/acs.est.7b04909

Zhang L, Zhou H, Chen X et al (2021) Study of the micromorphology and health risks of arsenic in copper smelting slag tailings for safe resource utilization. Ecotoxicol Environ Saf 219:112321. https:// doi.org/10.1016/j.ecoenv.2021.112321

Zheng LM (2017) The current new challenges facing global security governance. Sci Wealth 0:214

Publisher's note Springer Nature remains neutral with regard to jurisdictional claims in published maps and institutional affiliations. 